\title{
A Study on the Relationship between Seizure Recurrence and EEG for Epilepsy
}

\author{
Kyoung-Min Chae ${ }^{1}$, Hyun-Ho Sung ${ }^{2}$, Dae-Sik Kim ${ }^{2}$ \\ ${ }^{1}$ Department of Neurology, Seoul National University Hospital, Seoul 03080, Korea \\ ${ }^{2}$ Department of Clinical Laboratory Science, Dongnam Health University, Suwon 16328, Korea
}

\section{뇌전증 발작재발과 뇌파검사의 관계 연구}

\author{
채경민 ${ }^{1}$, 성현호 $^{2}$, 김대식 ${ }^{2}$ \\ ${ }^{1}$ 서울대학교병원 신경과, ${ }^{2}$ 동남보건대학교 임상병리과
}

\begin{abstract}
Epilepsy, characterized by enduring the predisposition to generate epileptic seizures, was conceptually defined in 2005 as a disorder of the brain. According to the international league against epilepsy in 2014 that there is a high risk of recurrence within 10 years. The existence of interictal epileptiform discharges (IEDs) at the Electroencephalography (EEG) is an important risk factor for a possible recurrence of seizures, disproving that the seizures may increase. The purpose of this study was to analyze the correlation between recurrent seizures and epilepsy EEG findings in patients with IEDs, which was carried out to serve as the basis for the EEG to predict the prognosis of patients with epilepsy. This study included 432 adults older than 20 years of age who care for patients with epilepsy at Seoul National University Hospital, between June 2007 and December 2010. The results showed no difference between men and women in the EEG epilepsy disease, but there was a difference between various age groups. Correlation analysis showed a negative correlation between recurrence of seizures and age; it showed a positive correlation between recurrence and IEDs. In addition, age was associated with a predictive power of $10.9 \%$ and IEDS showed a predictive power of $15 \%$ on recurrent seizures. Therefore, EEG is considered as a very important test in epilepsy diagnosis. Therefore, further studies are necessary on the relationship between seizure recurrence and EEG.
\end{abstract}

Key words: Electroencephalography, Epilepsy, Seizures

This is an Open Access article distributed under the terms of the Creative Commons Attribution Non-Commercial License (http://creativecommons.org/licenses/by-nc/4.0) which permits unrestricted non-commercial use, distribution, and reproduction in any medium, provided the original work is properly cited.

Copyright ( 2016 The Korean Society for Clinical Laboratory Science. All rights reserved.
Corresponding author: Dae-Sik Kim Department of Clinical Laboratory Science, Dongnam Health University, 50

Cheoncheon-ro 74-gil, Jangan-gu, Suwon 16328, Korea

Tel: 82-31-249-6413

Fax: 82-31-249-6410

E-mail: kdaesik@dongnam.ac.kr

Received: August 16, 2016 Revised $1^{\text {st. }}$ September 4, 2016

Revised $2^{\text {nd }}$ : September 27, 2016

Revised $3^{\text {rd: }}$ : September 28, 2016

Revised $4^{\text {th }}$ : October 25, 2016

Accepted: October 31, 2016

\section{서 론}

뇌전증의 개념은 간질발작이 지속적으로 발생하는 뇌변병으로 2005년에 정의 되었다. 2014년 국제항뇌전증연맹(international league against epilepsy, ILAE)은 뇌전증(epilepsy)을 24시간 이 상 간격을 두고 발생하는 2회 이상의 비유발성 및 반사성 발작 또는 1 회 비유발성 또는 반사성 발작을 보이고 향후 10 년 이내 재발 위험
이 높은 경우로 새롭게 정의를 하였다[1]. 뇌전증 발작은 과도한 비 정상적인 뇌의 신경활동으로 나타나는 증상이나 징후로 간단하게 설명할 수 있다[2]. 뇌전증 발작은 돌발적으로 발생하기 때문에 의 사의 문진 시 증상을 직접 관찰할 수 없으므로 환자 본인이나 보호 자를 통한 병력 청취가 중요하다[3]. 따라서 뇌전증 발작에 따른 신 경세포의 뇌전기 활동을 기록하여 뇌전증을 진단하는데 뇌파검사 (electroencephalogram, EEG)가 매우 유용한 검사이며, 뇌파에 
서 발작간 뇌전증양 발작파(interictal epileptiform discharges, IEDs)는 특징적인 모양으로 구분되는 파형으로 극파(spike), 다발 극파(polyspike), 예파(sharp wave), 극서파 복합체(spike and wave complex) 또는 예서파 복합체(sharp and wave complex) 등이 있고 이들의 존재여부는 발작 또는 뇌전증을 진단하는 데 결 정적인 도움을 준다[4]. IEDs 혹은 서파는 뇌전증을 분류하는데 진 단적 특이성으로 도움이 된다[5,6]. 뇌전증 환자에서 뇌파검사를 진단과 분류에 사용하는 것은 발작이 재발할 유무에 대한 예후를 알아보는데 뇌파검사를 어떻게 활용할 것인가에 대한 부분이 뇌전 증의 치료에 있어 매우 현실적이고 중요한 부분이다. 뇌전증 발작 재발의 중요한 위험인자로서 뇌파에서 IEDs의 존재는 발작 증상이 높게 나타날 수 있다는 것을 반영한다[7,8]. 그러나 뇌파검사는 첫 번째 시행하는 검사에서는 IEDs를 발견하는데 민감도가 낮기 때문 에[6], 반복적인 검사가 필요로 한다. 그러나 반복적인 뇌파검사를 실시하는데도 불구하고 발견을 못하는 경우도 있으며, 또한 증상이 없는 환자에게서도 지속적인 IEDs가 나타나기도 한다[9,10]. 따라 서, 뇌파검사는 뇌전증 환자에게서 발작재발의 예후를 판단하는데 있어 많은 연구가 필요할 것으로 생각되며, $\mathrm{EEG}$ 와 뇌전증의 전향 적인 연구가 부족하며, 특히 뇌전증에 관련된 진단 지침이 없어 실 제 임상에서 의사들은 개개인의 진료 경험에 의존하여 치료하고 있 는 실정이다[11,12]. 이에 본 연구는 뇌전증 환자에서 뇌파검사 소 견과IEDs에 따른 발작재발의 상관관계를 분석하여 뇌전증 환자의 예 후를 예측하기 위한 뇌파검사의 기초자료로 활용하고자 실시하였다.

\section{재료 및 방법}

\section{1. 연구대상}

본 연구는 2007년 6월부터 2010년 12월까지 경련으로 서울대 학교병원 신경과를 내원하여 뇌파검사를 시행한 후 뇌전증 진단을 받은 20 세 이상의 성인 432 명을 대상으로 하였다. 본 연구는 서울 대학교병원에 설치된 의학연구윤리심의위원회(IRB, Institutional Review Board)의 승인 하에 시행하였다(IRB Approval Number: $\mathrm{H}$-1504-094-666).

신체계측 및 혈압측정 신장 체중 자동 측정기기는 GL-150 (G-tech, Uijungbu, Korea) 사의 모델을 사용하였으며, 병동에 입 원해 있는 환자 중 거동이 불편한 환자의 신체계측은 신장은 줄자 로 측정하고 체중은 inbed scale로 측정하며, 외래에서는 자동화 기계를 사용하여 환자들이 직접 측정하였다.

\section{2. 뇌파 검사}

뇌파검사에 사용된 기기는 미국의 Comet (Grass Technologies,
Pleasanton, USA)를 사용하였고, 평균 기준 몽타주(average referential montage)로, 표본 주파수(sampling rate)는 $200 \mathrm{~Hz}$, frequency filter는 최고 $70 \mathrm{~Hz}$ 최저 $1.0 \mathrm{~Hz}$, 감도는 $150 \mu \mathrm{V} / \mathrm{pp}$, 교 류저항은 $10 \mathrm{k} \Omega$ 이하 조건하에 검사를 실시하였다. 전극의 배치는 1952년 국제뇌파학회에서 권장한 표준배치법인 국제 10 20법을 사용하였다. 뇌파검사는 발작간 뇌파검사를 시행하였으며 각성, 안정 폐안 상태만으로는 충분한 이상소견이 얻어지지 않으므로 개 폐안, 섬광자극, 과호흡, 수면부활법을 적용하였다. 의식이 불명확 하여 협조가 되지 않는 환자에서는 부활법을 적용하지 않고 시행하 였고, 수면은 자연수면을 하도록 하였다.

\section{3. 뇌파검사의 판독}

판독은 서울대병원 신경과의 뇌파 판독기준을 따라 서울대병원 신경과 전문의가 판독하였다. 뇌파소견은 Normal, Abnormal I, Abnormal II, Abnormal III로 조작적 정의를 하였다. 뇌파의 정상 소견을 Normal으로 하였으며, 판독의 기준을 배경 서파가 6 8 $\mathrm{Hz}$ 이거나 간헐적인 서파가 전반성으로 관찰되거나 정상 배경파와 함께 지속적인 서파가 나타날때를 Abnormal I로 판정하였으며, 배 경 서파가 $6 \mathrm{~Hz}$ 이하이거나 또는 간헐적인 서파가 국소성이거나 편 측성으로 관찰되거나 배경서파와 함께 지속적인 서파가 나타날 때 를 Abnormal II로 판정하였다. Abnormal III는 지속적인 서파 혹 은 IEDs로 판정하였다. 판정 결과는 후향적 조사를 실시하였으며, 뇌전증 발작 횟수는 없음(None), 1 회(1), 1 회 이상(1<)로 조작적 분류하였다.

\section{4. 통계 분석}

통계의 자료분석은 SPSS 버전 21.0 프로그램(SPSS, Chicago, Illinois, USA)을 사용하였다. 연구대상자들의 신체적 특성, 뇌파검 사에 관한 변인 등을 빈도분석하여 처리하였으며, 각각의 변인들의 집단에 따른 동질성분석으로 교차분석을 실시하였다. 모든 정량데 이터는 평균(M)과 표준편차(SD)를 산출하였고, 그에 따른 변인들 의 차이를 검정하기 위해 독립 $\mathrm{t}$-검정과 일원배치분석을 실시하였 다. 또한 변인들의 관련성을 입증하기 위하여 피어슨의 상관관계분 석을 실시하여 그에 따른 다중회귀분석을 실시하였다. 모든 통계적 유의수준은 $p<0.05$ 로 설정하였다. 판독은 서울대병원 신경과의 뇌파 판독기준을 따라 서울대병원 신경과 전문의가 판독하였다.

\section{결 과}

\section{1. 대상자의 일반적 특성}

연구대상자는 전체 432명 중남성이 225 (52.1\%)명, 여성이 207 
(47.9\%)명이었다. 연구대상자의 일반적 특성으로 성별에 따른 전체 연령의 평균과 표준편차는 $55.89 \pm 17.01$, 남성은 $56.21 \pm 18.61$, 여성은 $55.54 \pm 15.12$ 세로 통계적으로 유의한 차이가 없어 동일한 집단으로 분석되었다. 또한 신장과 체중 그리고 체질량지수(BMI) 는 남성과 여성의 신체적 특성에 따라 유의한 차이를 보였으며 $(p<0.05)$, 성별에 따른 혈압의 차이는 수축기와 이완기 모두 유의 한 차이를 보이지 않아 동일한 집단으로 분석되었다(Table 1).

\section{2. 성별에 따른 뇌파검사결과와 발작 재발 분포}

연구대상자의 성별에 따른 뇌파 검사결과의 분포는 전체 432 명 중 정상소견은 $122(28.2 \%)$ 로 나타났다. Abnormal I의 결과에는 101 (23.4\%)명, Abnormal II의 결과는 98 (22.7\%)명, Abnormal III의 결과는 111 (25.7\%)명으로 성별에 따른 분포는 남성 전체 225 명 중 정상이 62 (28\%), Abnormal I의 결과에는 56 (24.9\%)명, Abnormal II의 결과는 50 (22.2\%)명, Abnormal III의 결과는 56 (54.9\%)로 나타났다. 여성은 전체 207명 중 정상이 59 (28.5\%)명, Abnormal I의 결과에는 45 (21.7\%)명, Abnormal II 의 결과는 48 (23.2\%)명, Abnormal III의 결과는 55 (26.6\%)로 나타났다. 성별 에 따른 뇌파결과분석의 차이는 통계적으로 유의하지 않아 동일한 집단으로 분석되었다. 성별에 따른 발작재발의 분포는 발작이 없었
던 환자가 전체 $318(73.6 \%$ 명 중에서 남성은 161 (71.6\%)명, 여성 은 157 (75.8\%)명 이었으며, 1회 발작이 있었던 환자는 전체 59 (13.7\%)명 중 남성은 37 (15.1\%), 여성은 25 (12.1\%)의 분포를 나 타내었으며, 1 회 이상의 발작을 일으킨 환자는 전체 55 (12.7\%)명 중에서 남성은 $30(13.3 \%)$, 여성은 $25(12.1 \%)$ 로 나타났다. 성별에 따른 발작 재발의 통계적인 차이는 유의하지 않아 동일한 집단으로 나타났다. 결과는 Table 2에 제시하였다.

\section{3. 연령에 따른 뇌파검사결과와 발작 재발 분포}

연구대상자인 뇌전증 환자의 연령별 분포는 전체 432 명 중 가장 낮은 연령이 24 세였으며, 최 고령자는 96세였다. 연령에 따른 뇌파 검사 판독 결과의 차이는 정상소견과 Abnormal I, Abnormal II, Abnormal III각각 다른 집단으로 나타났으며, 통계적으로 유의하 였다 $(p<0.01)$. 연령에 따른 발작재발의 연령별 분포는 발작이 없 었던 집단과 1회 재발환자분포 그리고 2회 이상 발작이 있었던 환 자에 따라 차이가 있었다 $(p<0.01)$. 분포의 결과는 Table 3 에 제시 하였다.

\section{4. 연령과 뇌파결과 그리고 발작재발의 상관관계}

연구대상자의 연령과 발작재발과의 상관관계는 음의 상관관계

Table 1. General characteristics of subjects

\begin{tabular}{lcccc}
\hline & $\begin{array}{c}\text { Total } \\
\mathrm{n}=432\end{array}$ & $\begin{array}{c}\text { Male } \\
\mathrm{n}=225\end{array}$ & $\begin{array}{c}\text { Female } \\
\mathrm{n}=207\end{array}$ & $\mathrm{t}$ \\
\cline { 2 - 4 } Characteristic & \multicolumn{3}{c}{$\mathrm{M} \pm \mathrm{SD}$} & 0.41 \\
Age & $55.89 \pm 17.01$ & $56.21 \pm 18.61$ & $55.54 \pm 15.12$ & $7.78^{\star \star}$ \\
Height $(\mathrm{cm})$ & $161.59 \pm 14.79$ & $166.43 \pm 18.38$ & $156.33 \pm 6.09$ & $8.36^{\star \star}$ \\
Weight $(\mathrm{kg})$ & $63.38 \pm 16.59$ & $69.19 \pm 19.50$ & $57.06 \pm 9.23$ & $2.31^{*}$ \\
BMI $\left(\mathrm{kg} / \mathrm{m}^{2}\right)$ & $27.90 \pm 41.16$ & $32.09 \pm 56.68$ & $23.34 \pm 3.49$ & 0.83 \\
SBP & $117.64 \pm 22.08$ & $118.49 \pm 23.76$ & $116.72 \pm 20.11$ & 1.60 \\
DBP & $72.06 \pm 14.27$ & $73.12 \pm 14.27$ & $70.92 \pm 13.48$ & \\
\hline
\end{tabular}

${ }^{*} p<0.05,{ }^{* *} p<0.01$.

Abbreviation: BMI, body mass index SBP, systolic blood pressure; DBP, diastolic blood pressure.

Table 2. Distribution of the presence or absence of abnormal EEG findings and seizure recurrence by gender

\begin{tabular}{|c|c|c|c|c|c|}
\hline \multicolumn{2}{|c|}{ Characteristic } & \multirow{2}{*}{$\begin{array}{c}\text { Total } \\
\mathrm{n}=432(\%)\end{array}$} & \multirow{2}{*}{$\begin{array}{c}\text { Male } \\
\mathrm{n}=225(\%) \\
63(28.0)\end{array}$} & \multirow{2}{*}{$\begin{array}{c}\begin{array}{c}\text { Female } \\
\mathrm{n}=207(\%)\end{array} \\
59(28.5)\end{array}$} & \multirow{2}{*}{$\frac{x^{2}}{0.63}$} \\
\hline EEG & Normal & & & & \\
\hline & Abnormal I & $101(23.4)$ & $56(24.9)$ & $45(21.7)$ & \\
\hline & Abnormal ॥ & $98(22.7)$ & $50(22.2)$ & $48(23.2)$ & \\
\hline & Abnormal III & $111(25.7)$ & $56(24.9)$ & $55(26.6)$ & \\
\hline \multirow[t]{3}{*}{ Seizure recurrence } & None & $318(73.6)$ & $161(71.6)$ & $157(75.8)$ & 1.13 \\
\hline & 1 & $59(13.7)$ & $34(15.1)$ & $25(12.1)$ & \\
\hline & $1<$ & $55(12.7)$ & $30(13.3)$ & $25(12.1)$ & \\
\hline
\end{tabular}

1 , once; $1<$, more than two.

Abbreviation: EEG, electroencephalogram. 
Table 3. Distribution of the presence or absence of abnormal EEG findings and seizure recurrence by age

\begin{tabular}{|c|c|c|c|c|c|c|c|c|c|}
\hline \multicolumn{2}{|c|}{ Characteristic } & $\begin{array}{c}\text { Total }^{\dagger} \\
432(100)\end{array}$ & $\begin{array}{l}24 \sim 30 y r \\
29(3.3 \%)\end{array}$ & $\begin{array}{c}31 \sim 40 y r \\
67(9.8)\end{array}$ & $\begin{array}{l}41 \sim 50 \mathrm{yr} \\
79(15.0)\end{array}$ & $\begin{array}{l}51 \sim 60 \mathrm{yr} \\
82(19.0)\end{array}$ & $\begin{array}{l}61 \sim 70 y r \\
73(19.9 \%)\end{array}$ & $\begin{array}{l}71 \sim 96 \mathrm{yr} \\
102(33.1)\end{array}$ & $x^{2}$ \\
\hline \multirow[t]{4}{*}{ EEG } & Normal & $122(28.2)$ & $3(2.5)$ & $13(10.7)$ & $24(19.7)$ & 34 (27.9) & $23(18.9)$ & $25(20.5)$ & $37.05^{\text {** }}$ \\
\hline & Abnormal I & $101(23.4)$ & $14(13.9)$ & $25(24.8)$ & $16(15.8)$ & $9(8.9)$ & $13(12.9)$ & $24(23.8)$ & \\
\hline & Abnormal II & $98(22.7)$ & $3(3.1)$ & $12(12.2)$ & $23(23.5)$ & $18(18.4)$ & $16(16.3)$ & $26(26.5)$ & \\
\hline & Abnormal III & $111(8.1)$ & $9(15.3)$ & $17(15.3)$ & $16(14.4)$ & $21(18.9)$ & $21(18.9)$ & $27(24.3)$ & \\
\hline \multirow{3}{*}{$\begin{array}{l}\text { Seizure } \\
\text { recurrence }\end{array}$} & None & $318(73.6)$ & $14(4.4)$ & 37 (11.6) & $55(17.3)$ & 57 (17.9) & 62 (19.5) & $93(29.2)$ & $50.25^{\star \star}$ \\
\hline & 1 & $59(13.7)$ & 7 (11.9) & $11(18.6)$ & $13(22.0)$ & $15(25.4)$ & $6(10.2)$ & 7 (11.9) & \\
\hline & $1<$ & $55(12.7)$ & $8(6.7)$ & 19 (15.5) & $11(18.3)$ & $10(19.0)$ & $5(16.9)$ & $2(23.6)$ & \\
\hline
\end{tabular}

${ }^{\dagger}$ Total, n (\%).

${ }^{\star *} p<0.01$

Abbreviation: 'See table 2'.

Table 4. Correlation of age, EEG and seizure recurrence

\begin{tabular}{lcccc}
\hline & Age & EEG & $\begin{array}{c}\text { Seizure } \\
\text { Recurrence }\end{array}$ & IDE \\
\hline Age & 1 & & & \\
EEG & -0.01 & 1 & & \\
Seizure Recurrence & $-0.33^{\star *}$ & $0.21^{\star *}$ & 1 & \\
IDEs & -0.72 & $0.79^{\star *}$ & $0.20^{\star *}$ & 1 \\
\hline
\end{tabular}

${ }^{* *} p<0.01$.

Abbreviation: 'See table 2'.

로 연령이 증가함에 따라 발작재발이 감소하는 것으로 나타났으며, 통계적으로 유의하였다 $(p<0.01)$. 뇌파검사결과의 abnormal 수 준이 증가함에 따라 발작재발도 증가하는 양의 관계로 나타났으며, 통계적으로 유의하였다 $(p<0.01)$. 각 변인에 따른 상관관계 결과 는 Table 4과 같다.

\section{5. 뇌파 결과와 연령에 따른 발작재발과의 관계}

연구대상자의 연령과 뇌전증 발작재발과의 상관관계와 뇌파검 사결과의 abnormal 수준에 따른 뇌전증 발작재발과 상관관계에 따라 회귀분석을 실시한 결과 Dubin-Watson의 값이 1.99로 회귀 모형에 적합하였고 뇌전증 환자의 연령이 발작재발에 미치는 영향 은 t값이 19.62 로 나타나 영향을 미치는 것으로 나타났으며, $10.9 \%$ 의 설명력을 나타내었다 $(p<0.01)$. 뇌파검사결과의 abnormal 수 준이 따른 발작재발에 미치는 영향은 t값이 14.491 로 통계적으로 유의하게 나타나 관련이 있었으며, $15 \%$ 의 설명력을 나타내었다 $(p<0.01)$. 결과는 Table 5 와 같다.

\section{고 찰}

본 연구는 2007년 6월부터 2010년 12월까지 경련으로 서울대 학교병원 신경과를 내원하여 뇌파검사를 시행한 후 뇌전증 진단을 받은 20 세 이상의 성인 432 명을 대상으로 뇌파검사에 따른 판독소
Table 5. Regression of Seizure Recurrence by Age and EEG

\begin{tabular}{|c|c|c|c|c|c|}
\hline \multirow{2}{*}{ Variables } & \multicolumn{5}{|c|}{ Seizure Recurrence } \\
\hline & B & SE & $\mathrm{t}$ & $F$ & $D \sim W: 1.902$ \\
\hline Age & 2.155 & .110 & $19.62^{*}$ & $52.82^{\star *}$ & $\begin{array}{c}r: 0.331 \\
\mathrm{R}^{2}: 0.109 \\
\mathrm{~F}: 52.82\end{array}$ \\
\hline EEG & 1.840 & .127 & $14.49^{\star \star}$ & $38.45^{\star *}$ & $\begin{array}{c}r: 0.390 \\
R^{2}: 0.152 \\
F: 38.45\end{array}$ \\
\hline
\end{tabular}

${ }^{\star *} p<0.01$

Abbreviation: D W, Dubin-Watson. See table 2.

견과 발작재발의 상관관계분석을 서울대학교병원에 설치된 의학 연구윤리심의위원회의 승인 하에 후향적 연구를 시행하였다. 2012년 국내 의무기록조사를 통한 뇌전증 환자의 인구학적 및 임 상적 특성에 관한 연구로 진행된 2,000명 이상의 대규모 환자를 대 상으로 한 국내 연구에서는 남성에서 뇌전증의 치료 유병률이 높았 다. 이러한 양상은 유럽 및 북아메리카 연구와 인도와 베트남의 연 구에서도 나타났다. 반대로, 아프리카와 남미 연구에서는 여성에 서 유병률이 높게 나타나기도 하였다. 남성에서 유병률이 높은 것 은 남성에서 외상을 비롯한 뇌손상이 잘 생기기 때문으로 생각되 며, 50 대 이상에서 특히 격차가 커지는 이유도 같은 의미로 설명하 고 있다[13]. 본 논문에서도 뇌파검사결과와 판독소견을 분석한 결 과 전체 432건 중 남성이 225 (52.1\%)명, 여성이 207 (47.9\%)명으 로 조사되어 남성이 높게 나타나는 경향을 보였다. 이번에 실시한 연구 대상자는 통계적으로 성별에 따른 연령과 BMI그리고 혈압에 차이가 없는 동일한 집단으로 분석되었다. 뇌파 검사결과의 차이는 전체 432명 중 2007년부터 2010년까지 발작재발이 없었던 환자 들의 집단에서 정상소견이 나타난 normal의 결과에는 122 (28.2\%)명으로 나타났다. Abnormal I의 결과에는 101 (23.4\%)명, Abnormal II의 결과는 98 (22.7\%)명, Abnormal III의 결과는 111 (25.7\%)명으로 또한, 성별에 따른 분포는 통계적으로 유의하지 않 아 동일한 집단으로 분석되었다. 이러한 인구통계학적 분포에 따른 
연구 결과, 뇌전증 환자의 뇌파 결과와 발작 재발의 관계에서 연령 을 독립변수로 종속변수인 뇌파 판독소견결과의 분류인 Normal, Abnormal I, Abnormal II, Abnormal III 수준의 분포는 통계적으 로 각각 차이가 있는 것으로 나타났다 $(p<0.01)$. 연령에 따른 발작 재발의 분포차이 또한 각각의 수준에 따라 통계적으로 유의한 차이 를 나타냈다 $(p<0.01)$. 선행논문에 따르면 뇌전증의 치료 유병률 은 연령에 차이를 나타내었으며, $30 \sim 40$ 대에서 상대적으로 낮은 $\mathrm{U}$ 자 모양의 분포를 보였다. 이는 소아기에 생겼다가 호전되는 소아 뇌전증증후군들과, 고령에서 생기는 여러 뇌손상에 기인하는 증후 성 뇌전증 때문으로 해석할 수 있다고 설명하고 있다[13]. 본 연구 에서는 가장 많은 빈도를 차지하는 비율로 71 96세 집단이었으 며, Abnormal II 집단 98명 중 26 (26.5\%)명 그리고 Abnormal III 집단 111 명 중 27 (24.3\%)명으로 나타났으며, 전체적으로 낮은 분 포를 차지하는 집단은 뇌파결과소견에 따른 24 30세 집단으로 나 타나 전술한 2012년의 선행논문과 같은 결과를 나타내었다. 또 다 른 선행논문을 살펴보면 급성 발작을 가지고 있는 114 명의 신생아 와 어린이를 1 년 동안 추적 관찰한 결과 $10 \%$ 가 뇌전증으로 진단되 었으며, 발작재발은 뇌전증의 위험을 증가시키는 것으로 나타났다 [14]. 이번 연구에서는 24 세 이하의 연령층이 없었으므로, 재 연구 가 필요하다고 생각한다. 뇌전증 발작은 일반적으로 간질전신발작 혹은 대발작을 말한다. 부분 발작은 뇌의 개별 영역에서의 운동근 육, 감각, 행동, 또는 지각 현상의 다양한 부분으로 나타난다[15]. 전세계 인구중 약 $1 \%$ 가 뇌전증으로 고통 받고 있으며, 뇌전증 환자 의 30\%는 약물 치료에 효과가 없는 것으로 알려져 있어 $\mathrm{EEG}$ 결과 의 주의 깊은 분석은 가치 있는 뇌전증 장애를 일으키는 메커니즘 의 개선 된 이해를 제공 할 수 있다[16]. 2016년 성인 대상의 EEG의 연구에 의하면 민감도와 특이도 $95 \%$ 신뢰 구간에서 각각 $17.3 \%$ 및 94.7\%였으며, 아동 대상의 $\mathrm{EEG}$ 의 연구에 의하면 민감도와 특이도 는 각각 $57.8 \%$ 와 $69.6 \%$ 였다. 성인의 일반적인 $\mathrm{EEG}$ 결과에서 우도 비율 즉, 확률값에 기초하여 $50 \%$ 의 IEDs를 가진 대상자는 재 발작 이 $77 \%$ 의 확률로 나타났으며, 어린이에게서는 $66 \%$ 의 확률로 나타 났다[17]. 따라서 EEG 검사 유용성에 대한 심도 깊은 고찰이 필요 할 것으로 생각한다. 특히, 이번 연구대상자의 연령과 발작재발과 의 상관관계는 음의 상관관계로 연령이 증가함에 따라 발작재발이 감소하는 것으로 나타났는데, 이러한 결과는 일반적으로 노인에서 의 뇌전증은 진단은 어려운 부분이며, Hauser 등(1992)의 연구 에 따르면 40대에서 $30 / 100,000$ 의 빈도를 보이는 반면에 80 대가 되 면 140/100,000으로 증가하여 전체적으로는 노인의 약 $1 \%$ 로 추 산된다. 2000년도의 전향적인 연구에서는 전체인구의 1.7 5.4\% 로 보고되었다는 점을 고려할 필요가 있다[18]. 즉, 소아에서는 전 신성 경련이 흔한 반면에 노인에서는 국소성 발작이 흔한 이유로
추산된다[13]. 치매나 다른 신경계질환을 갖는 노인의 병력, 비발 작성간질지속증(non-convulsive status epilepticus, NCSE) 등 에서 간질의 진단이 곤란하며, 복합부분발작(complex partial seizure, $\mathrm{CPS}$ )이나 의식의 저하, 장기간 의식소실, 발작적인 동통 증후군 등이 뇌파상에서 간질파와 동반되어 자주 나타나기 때문이 다. 또한, 경련이 동반되어 나타나는 반복적인 운동은 구강안면운 동장애나안정떨림(resting tremor) 등과 구별하기가 곤란하며, 노 인에게서 나타나는 부정맥, 저혈당, 당뇨성 혼수, 좌위성 저혈압, 경동맥동과민, 약물 부작용, 혈관미주신경실신 등을 감별해야만 한다. 즉, 노인이 경련으로 입원하거나 치료 중에 경련이 초발한 경 우 대부분은 기질적인 원인을 잘 분석해야 할 것으로 사료된다. 일 반적으로 노인의 뇌파소견은 소아의 특정 간질증후군에서 관찰되 는 것과 같은 특징적인 소견을 보이지 않아 진단적 가치가 다소 떨 어지는 것으로 알려져 있다. 더욱이 정상 노인에서도 미만성 서파 는 흔하게 나타날 수 있는 것으로 알려져 있다[19]. 그러나 뇌파의 IEDs의 임상적 유용성은 환자가 간질을 가질 임상적 가능성이 높을 수록 매우 커질 수 있으며, 실제 임상에서는 간질과 감별 진단해야 할 질환을 가진 환자를 대상으로 뇌파검사를 시행하기 때문에 대상 환자에서 실제 간질을 가진 경우가 대부분을 차지할 것이라 생각되 기 때문에 간질에 대한 IEDs의 긍정적인 가치는 매우 높을 수밖에 없다. 뇌전증의 통계적 위험요인으로는 성별, 발작의 발병 연령, 발 작 지속 기간, 무발작 기간, 치료 전 발작 횟수, 발작이 조절되기까 지 투여된 항경련제의 수, 항경련제의 감량 기간과 중단 연령, 투여 기간, 약물 투여 중 발작의 발생 여부, 발작의 원인, 방사선학적 이 상 여부, 열성 경련의 과거력과 간질의 가족력, 간질 중첩증의 유무, 신경학적 이상 여부, 진단시와 항경련제 중단 전 뇌파 검사의 이상 여부와 변화 정도 등으로 정리할 수 있다. 이번 연구에서 이러한 위 험요소인 연령이 뇌파결과와 발작재발에 영향을 미치는 것으로 나 타났다. 또한, 뇌파결과는 발작재발에 유의한 영향을 나타내고 있 는 결과를 나타내었다. 그러나 뇌전증 위험 요인으로 치료 중 발작 재발 여부에 관련된 선행연구는 찾아볼 수 없다. 그러나 임상에서 는 적당한 기간의 무발작 후에 항경련제의 중단을 결정하는데 발작 의 재발 가능성을 고려하고 있다[20]. 이러한 선행 연구들을 종합해 보면 뇌파이상은 뇌전증 재발을 예측하는 인자인 듯하고 치료직전 실시한 뇌파검사와 치료 중 뇌파검사 그리고 약물을 중단한 후 뇌 파결과를 비교해 보는 연구가 필요할 것으로 생각된다. 뇌파검사는 임상에서 사용하는 뇌전증 진단에 매우 중요한 검사이다. 뇌파는 뇌전증의 원인을 확인하는 데 도움이 되며, 발작 후 재발 위험의 추 정을 할 수 있으며, 뇌전증 증후군의 진단과 뇌전증 수술 전 평가를 할 수 있는 표준으로 하고 있다[21]. 전술한 바와 같이 본 연구는 뇌 전증 환자를 대상으로 하였기 때문에, 치료받고 있지 않은 뇌전증 
환자는 조사에서 제외될 수 밖에 없는 한계점이 있다. 또한 본 연구 에서는 발작의 형태를 배제 하였다. 이런 부분을 보완하기 위해서 는 향후 대면 연구가 필요하다고 생각하며, 본 연구는 국내의 뇌전 증 연구의 일차적 기초자료 연구로 뇌전증 환자의 뇌파소견에 따른 임상적인 특성에 대한 기본적인 연구를 시행하였다. 향후 보다 의 미 있는 임상 자료가 되기 위하여 발병률에 따른 뇌파결과와 치료 중 뇌파결과와 발작재발 그리고 치료 후 발작재발 등을 연구해야 할 필요성이 있으며, 임상 경과 추적에 대한 감시시스템을 갖추는 것이 필요할 것으로 생각된다.

\section{요 약}

뇌전증의 개념은 간질발작이 지속적으로 발생하는 뇌변병으로 2005년에 정의 되었다. 2014년 국제항뇌전증연맹에서는 새로운 정의를 내렸으며, 10 년 이내 재발 위험이 높다고 하였다. 뇌전증 발 작재발의 중요한 위험인자로서 뇌파에서 IEDs의 존재는 발작 증상 이 높게 나타날 수 있다는 것을 반영한다. 본 연구는 뇌전증 환자에 서 뇌파검사 소견과 IEDs에 따른 발작재발의 상관관계를 분석하여 뇌전증 환자의 예후를 예측하기 위한 뇌파검사의 기초자료로 활용 하고자 실시하였다. 연구결과, 뇌전증 질환의 남녀 차이는 없었으 며, 연령의 분포 차이는 있었다. 상관관계 분석결과 연령에 따라 발 작재발은 음의 상관관계였으며, IEDs에 따라 발작재발은 양의 상 관관계를 나타내었다. 또한 통계적으로 연령은 발작재발에 $10.9 \%$ 의 영향을 나타내었고, IEDs는 발작재발에 $15 \%$ 의 설명력을 나타 내었다. 따라서 뇌파검사는 임상에서 사용하는 뇌전증 진단에 매우 중요한 검사로 판단되며, 향후 보다 의미 있는 임상 자료가 되기 위 하여 발병률에 따른 뇌파결과와 치료 중 뇌파결과와 발작재발 그리 고 치료 후 발작재발 등을 지속적으로 연구해야 할 것으로 생각된다.

\section{Acknowledgements: None}

Funding: This study was financially supported by Dongnam Health University.

Conflict of interest: None

\section{References}

1. Fisher RS, Acevedo C, Arzimanoglou A, Bogacz A, Cross JH, Elger CE, et al. ILAE official report: a practical clinical definition of epilepsy. Epilepsia. 2014;55(4):475-482.

2. Fisher RS, Boas WVE, Blume W, Elger C, Genton P, Lee P, et al.
Epileptic seizures and epilepsy: definitions proposed by the International League Against Epilepsy (ILAE) and the International Bureau for Epilepsy (IBE). Epilepsia. 2005;46(4):470-472.

3. Noachtar S, Remi J. The role of EEG in epilepsy: a critical review. Epilepsia. 2009;15:22-33.

4. Pillai J, Sperling MR. Interictal EEG and the diagnosis of epilepsy. Epilepsia. 2006;47:14-22.

5. Rugg-Gunn FJ, Harrison NA, Duncan JS. Evaluation of the accuracy of seizure descriptions by the relatives of patients with epilepsy. Epilepsy Res. 2001;43(3):193-199.

6. Smith, SJM. EEG in the diagnosis, classification, and management of patients with epilepsy. Journal of Neurology, Neurosurgery \& Psychiatry. 2005;76(2):222-227.

7. Bauer G, Trinka E. Nonconvulsive status epilepticus and coma. Epilepsia. 2010;51(2):177-190.

8. Wirrell EC. Prognostic significance of interictal epileptiform discharges in newly diagnosed seizure disorders. J Clin Neurophysiol. 2010;27(4):239-248.

9. Theodore $\mathrm{WH}$, Sato S, Porter RJ. Serial EEG in intractable epilepsy. Neurology. 1984;34(7):863-867.

10. Park SC. Controversies in usefulness of EEG for clinical decision in epilepsy: Pros. and Cons. Korean J Clin Neurophysiol. 2007; 9(9):59-62.

11. Lodder SS, Askamp J, van Putten MJ. Inter-ictal spike detection using a database of smart templates. Clin Neurophysiol. 2013; 124(12):2328-2335.

12. Pearce KM, Cock HR. An audit of electroencephalography requests: use and misuse. Seizure. 2006;15(3): 184-189.

13. Lee SY, Jung KY, Lee IK, Yi SD, Cho YW, Kim DW, et al. Prevalence of treated epilepsy in Korea based on national health insurance data. J Korean Med Sci. 2012;27(3):285-290.

14. Fox CK, Mackay MT, Dowling MM, Pergami P, Titomanlio L, Deveber G. Prolonged or recurrent acute seizures after pediatric arterial ischemic stroke are associated with increasing epilepsy risk. Dev Med Child Neurol. 2016;Jul:16. doi: 10.1111/ dmcn.13198. [Epub ahead of print].

15. Traulli A. Neurology. 1st ed. New York: Springer; 2016. p309336.

16. Adeli H, Zhou Z, Dadmehr N. Analysis of EEG records in an epileptic patient using wavelet transform. J Neurosci Methods. 2013;123(1):69-87.

17. Bouma HK, Labos C, Gore GC, Wolfson C, Keezer MR. The diagnostic accuracy of routine electroencephalography after a first unprovoked seizure. Eur J Neurol. 2016;23(3):455-463.

18. Ramsay RE, Pryor F. Epilepsy in the elderly. Neurology. 2000;55(1):9-14.

19. Drury I, Beydoun A. Pitfalls of EEG interpretation in epilepsy. Neurol Clin. 1993;11:857-881.

20. Kim HB, You SJ, Ko TS. Outcome after discontinuation of antiepileptic drugs in well controlled epileptic children-recurrence and related risk factors. Korean J Pediatr. 2004;47(1): 66-75.

21. Rosenow F, Klein KM, Hamer HM. Non-invasive EEG evaluation in epilepsy diagnosis. Expert Rev Neurother. 2015;15(4): 425-444. 